\title{
BMJ Open Lipid profiles and determinants of total cholesterol and hypercholesterolaemia among 25-74 year-old urban and rural citizens of the Yangon Region, Myanmar: a cross-sectional study
}

To cite: Htet AS, Kjøllesdal MK, Aung WP, et al. Lipid profiles and determinants of total cholesterol and hypercholesterolaemia among 25-74 year-old urban and rural citizens of the Yangon Region, Myanmar: a crosssectional study. BMJ Open 2017;7:e017465. doi:10.1136/ bmjopen-2017-017465

- Prepublication history and additional material for this paper are available online. To view these files, please visit the journal online (http://dx.doi. org/10.1136/bmjopen-2017017465).

Received 25 April 2017 Revised 6 September 2017 Accepted 15 September 2017

CrossMark

For numbered affiliations see end of article.

Correspondence to

Dr Aung Soe Htet;

aungsh@gmail.com

\section{ABSTRACT}

Objective The first is to estimate the prevalence

of dyslipidaemia (hypercholesterolaemia,

hypertriglyceridaemia, high low-density lipoprotein (LDL)

level and low high-density lipoprotein (HDL) level), as well

as the mean levels of total cholesterol, triglyceride, LDL

and HDL, in the urban and rural Yangon Region, Myanmar.

The second is to investigate the association between urban-rural location and total cholesterol.

Design Two cross-sectional studies using the WHO STEPS methodology.

Setting Both the urban and rural areas of the Yangon Region, Myanmar.

Participants A total of 1370 men and women aged 25-74 years participated based on a multistage cluster sampling. Physically and mentally ill people, monks, nuns, soldiers and institutionalised people were excluded.

Results Compared with rural counterparts, urban dwellers had a significantly higher age-standardised prevalence of hypercholesterolaemia ( $50.7 \%$ vs $41.6 \%$; $p=0.042)$ and a low HDL level $(60.6 \%$ vs $44.4 \% ; p=0.001)$. No urban-rural differences were found in the prevalence of hypertriglyceridaemia and high LDL. Men had a higher age-standardised prevalence of hypertriglyceridaemia than women $(25.1 \%$ vs $14.8 \%$; $p<0.001)$, while the opposite pattern was found in the prevalence of a high LDL (11.3\% vs $16.3 \% ; p=0.018)$ and low HDL level $(35.3 \%$ vs $70.1 \% ; p<0.001)$. Compared with rural inhabitants, urban dwellers had higher age-standardised mean levels of total cholesterol $(5.31 \mathrm{mmol} / \mathrm{L}$, SE: 0.044 vs $5.05 \mathrm{mmol} / \mathrm{L}$, $0.068 ; p=0.009)$, triglyceride $(1.65 \mathrm{mmol} / \mathrm{L}, 0.049 \mathrm{vs}$ $1.38 \mathrm{mmol} / \mathrm{L}, 0.078 ; \mathrm{p}=0.017)$, LDL ( $3.44 \mathrm{mmol} / \mathrm{L}, 0.019 \mathrm{vs}$ $3.16 \mathrm{mmol} / \mathrm{L}, 0.058 ; p=0.001)$ and lower age-standardised mean levels of $\mathrm{HDL}(1.11 \mathrm{mmol} / \mathrm{L}, 0.010 \mathrm{vs} 1.25 \mathrm{mmol} / \mathrm{L}$, $0.012 ; p<0.001)$. In linear regression, the total cholesterol

\section{Strengths and limitations of this study}

- The lipid profile of populations in Myanmar is scarcely studied.

- Response rates $(86 \%$ in urban areas and $84 \%$ in rural areas) were high.

We did not assess the fat composition of the diet of the participants.

- There was a lack of information about awareness, treatment and the control of high blood cholesterol.

was significantly associated with an urban location among men, but not among women.

Conclusion The mean level of total cholesterol and the prevalence of hypercholesterolaemia were alarmingly high in men and women in both the urban and rural areas of Yangon Region, Myanmar. Preventive measures to reduce cholesterol levels in the population are therefore needed.

\section{INTRODUCTION}

Cardiovascular disease (CVD) is a major cause of mortality in both developed and developing countries. ${ }^{12}$ High blood cholesterol is one of its primary risk factors, with the global burden of diseases estimating that high blood cholesterol alone accounted for 4.0 million deaths and 88.7 million disability-adjusted life years globally. ${ }^{3}$ In the South-East Asia Region (SEAR) high blood cholesterol has contributed to $6.6 \%$ of total deaths, ${ }^{4}$ whereas in developed countries the blood cholesterol level has been high, but is now decreasing. ${ }^{5}$ 
However, an increasing trend in blood cholesterol level has been observed in developing countries, including in both SEAR countries and globally. ${ }^{35}$ A previous study from 2008 has estimated the prevalence of hypercholesterolaemia to be $39 \%$ globally and $29 \%$ in the SEAR. ${ }^{6} \mathrm{~A}$ STEP survey in the Yangon Region, Myanmar, reported that $26.2 \%$ of the population lived with hypercholesterolaemia in $2003 .{ }^{7}$

The occurrence of hypercholesterolaemia can be reduced by changing one's dietary pattern to a lower total fat intake and an increased ratio of polyunsaturated or monounsaturated fatty acids to saturated fatty acids, and by increasing physical activitiy. ${ }^{8-11}$ A $10 \%$ reduction in blood cholesterol at the age of 40 years can be half the risk of ischaemic heart diseases within 5 years, and $20 \%$ at the age of $70 .{ }^{12}$ Although a previous study from the Yangon Region showed a high prevalence of hypercholesterolaemia, little is still known about dyslipidaemia in Myanmar. In the present study, we aim at presenting the distribution of total cholesterol (TC) and the prevalence of hypercholesterolaemia in the urban and rural parts of Yangon Region of Myanmar, as well as investigating the association between TC and an urban-rural location. Furthermore, we also aim at estimating the prevalence of the hypertriglyceridaemia, high low-density lipoprotein (LDL) level, the low high-density lipoprotein (HDL) level and the mean levels of triglyceride (TG), LDL and HDL by sociodemographic factors.

\section{Populations and methods}

In 2013 and 2014, two cross-sectional studies applying similar methods were conducted in the urban and rural areas of Yangon Region, respectively. The population of the Yangon Region, which is the most populated area in Myanmar, is 7.4 million, in which 5.2 million reside in urban areas and 2.2 million in rural areas. ${ }^{13}$

The study applied WHO STEPS methodology, ${ }^{14}$ including three STEPS. STEP 1 is a questionnaire part for sociodemographic information such as age, sex, education, income, behavioural characteristics of tobacco use, alcohol consumption, nutrition, physical activity and diagnoses of hypertension and diabetes. In STEP 2, anthropometry and blood pressure are measured, while in STEP 3 fasting venous blood is drawn to assess the concentration of TC, TG and HDL.

Both men and women aged 25-74 years were included in the study, but those who were deemed to be too physically and mentally ill to participate were not invited. Monks, nuns, soldiers and institutionalised people were not invited to participate in the study.

The sample size was estimated using the WHO STEPS sample size calculator, ${ }^{15}$ hence we planned to invite 800 for each study (ie, 1600 in total). The details of the sample size calculation have been published elsewhere. ${ }^{16}{ }^{17}$ The sampling adopted a multistage cluster sampling method, and during the first stage, six townships from urban areas and six townships from rural areas were randomly selected. Five wards (urban township units) from each of the selected urban townships and five villages (rural township units) from each of the selected rural townships were randomly chosen, thus making a total of 30 wards and 30 villages. From each selected ward and village, 26-27 households were randomly chosen from a list of all households in the wards and villages. From each household, the eligible members were listed, and one was randomly invited to participate in the study. Stratification on gender was also done. With the equal gender composition, we invited 804 from urban areas and 804 from rural areas, comprising a total of 1608 invitees. Among them, 755 (94\% response) from urban areas and 731 (91\% response) in rural areas took part in the study. All three STEPS were completed by a total of 691 (86\%) from urban areas and $679(84 \%)$ from rural areas. The participant recruitment process was shown in the online supplementary figure 1. Non-responses in STEP 1 and STEP 2 were due to 'Not willing' and 'Busy'. The main reason for non-participation in STEP 3 was due to 'being afraid of blood tests'. Pregnant women (3 from urban areas and 10 from rural areas) were excluded in the analyses since physiological changes in pregnancy may have influenced biochemical values.

\section{Data collection and measurements}

Five trained medical doctors collected the data in each survey. One of them took part in both data collections, and in both surveys identical methods were applied, using the WHO STEPS guidelines. ${ }^{14}$ Participants were interviewed face-to-face with a questionnaire before blood pressure, body height, weight, and waist and hip circumferences were measured. ${ }^{14}$ The next morning, participants were asked to attend a nearby health facility or survey site after 10 hours of overnight fasting. Venous blood samples were collected using a lipid tube and glucose tube, and stored in cold boxes with ice and then transported to the National Health Laboratory, Yangon, a reference laboratory for the Ministry of Health. Blood samples were analysed less than 3 hours after drawing blood.

Serum concentrations of TC, TG and HDL were determined by using the enzymatic colorimetric test, while the serum concentration of LDL was calculated from the Friedewald equation ${ }^{29}$ : 'Low-density lipoprotein=TCHDL-TG/2.17 (mmol/L)'. Fasting blood glucose was investigated by the enzymatic reference method with hexokinase.

\section{VARIABLES}

Hypercholesterolaemia was defined according to the National Cholesterol Education Programme guidelines: TC level $\geq 5.17 \mathrm{mmol} / \mathrm{L}^{18}$ Hypertriglyceridaemia was defined as a TG level $\geq 2.0 \mathrm{mmol} / \mathrm{L},{ }^{14}$ low HDL as $<1.03 \mathrm{mmol} / \mathrm{L}$ in men and $<1.28 \mathrm{mmol} / \mathrm{L}$ in women, and a high LDL as $\geq 4.13 \mathrm{mmol} / \mathrm{L} .{ }^{18}$ Severe hypercholesterolaemia was defined as an LDL level $\geq 5.0 \mathrm{mmol} / \mathrm{L} .{ }^{19} 20$

Education level was categorised into four groups: no formal school, less than and primary school completed 
(1-5 years), secondary to high school completed (6-11 years) and higher education ( $>11$ years). Daily individual income was categorised into three groups according to the World Bank's cut-off of poverty lines of US $\$ 1.90 /$ day and US $\$ 3.10 /$ day. $^{21}$

\section{Behavioural risk factors}

Those who currently smoked tobacco on a daily basis were regarded as daily smokers. ${ }^{14}$ On average, the cut-off for a low fruit and vegetable intake was set to less than five servings (approximately $80 \mathrm{~g}$ in one serving) of fruits and vegetables per day. ${ }^{14}$ Using metabolic equivalent of tasks (MET) from work, transport and leisure activity, low physical activity was defined as those who had a vigorous activity (20 min) less than 3 days/week, or a moderate activity less than 5 days/week ( $\geq 600$ MET-minutes). ${ }^{14}$

\section{Metabolic risk factors}

Overweight was defined as having a body mass index (BMI) of $>25.0 \mathrm{~kg} / \mathrm{m}^{2}$ and obesity as a BMI of $\geq 30 \mathrm{~kg}$ / $\mathrm{m}^{2} .{ }^{14}$ Hypertension was defined as having an average systolic blood pressure of $\geq 140 \mathrm{~mm} \mathrm{Hg}$ and/or a diastolic blood pressure of $\geq 90 \mathrm{~mm} \mathrm{Hg}$ or self-reported medication. ${ }^{14}$ Mean blood pressure was computed from the average of the second and third readings.

Diabetes mellitus (DM) was defined as a fasting blood glucose level of $\geq 7 \mathrm{mmol} / \mathrm{L}$ or a self-reported DM. ${ }^{22}$

\section{STATISTICAL METHODS}

Epidata software V.3.1 was used for double data entry, whereas data management and statistical analysis were performed by using STATA/IC V.14.0. We declared complex survey data by using 'svyset' and the survey prefix command 'svy' was used in the analysis in order to incorporate the complex survey design except for sociodemographic characteristics (table 1). Prevalence and mean values were age standardised according to the 2014 census population, ${ }^{13}$ and expressed as a $95 \%$ CI and SE, respectively. Statistical differences between proportions were computed using a Wald test (tables 2 and 3), and we used multivariate linear regression to investigate the association between urban-rural location and TC. The goodness of fit of the model and interaction were checked, and we discovered an interaction between location and sex. Small deviations from linearity of age were also detected, and no observations with high influences were detected. The linear regression analyses of the association between an urban-rural location and TC were based on a drawing of a directed acyclic graph: sex, age, education and income were identified as confounders, and then adjusted for in order to estimate the total effect of the urban-rural location on TC (model 1, table 4). Smoking, a low fruit and vegetable intake, low physical activity, overweight and obesity, hypertension and diabetes were all identified as mediators. These variables, together with the confounders, were included in analyses of the direct effect of urban-rural location on TC (model 2, table 4). Due
Table 1 Sociodemographic characteristics of urban and rural 25-74 year-old citizens of the Yangon Region, Myanmar

Total

Urban ( $n=691)$ Rural $(n=679) \quad(n=1370)$

\begin{tabular}{|c|c|c|c|}
\hline \multicolumn{4}{|c|}{ Gender (n (\%)) } \\
\hline Male & $338(48.9)$ & $342(50.4)$ & $680(49.6)$ \\
\hline Female & $353(51.1)$ & $337(49.6)$ & $690(50.4)$ \\
\hline \multicolumn{4}{|c|}{ Age (mean years $\pm S D)$} \\
\hline Male & $50.8 \pm 13.7$ & $47.0 \pm 12.5$ & $48.9 \pm 13.2$ \\
\hline Female & $47.6 \pm 12.4$ & $46.2 \pm 12.4$ & $46.9 \pm 12.4$ \\
\hline Total & $49.2 \pm 13.2$ & $46.6 \pm 12.4$ & $47.9 \pm 12.9$ \\
\hline \multicolumn{4}{|c|}{ Age group (proportion \%) } \\
\hline $25-34$ & $123(17.8)$ & $136(20.0)$ & $259(18.9)$ \\
\hline $35-44$ & $143(20.7)$ & $172(25.3)$ & 315 (23.0) \\
\hline $45-54$ & $159(23.0)$ & $167(24.6)$ & $326(23.8)$ \\
\hline $55-64$ & $164(23.7)$ & $142(20.9)$ & $306(22.3)$ \\
\hline $65-74$ & $102(14.8)$ & $62(9.1)$ & $164(12.0)$ \\
\hline
\end{tabular}

Education level ( $\mathrm{n}(\%))$

\begin{tabular}{|c|c|c|c|}
\hline $\begin{array}{l}\text { No formal } \\
\text { education }\end{array}$ & $18(2.6)$ & $68(10.0)$ & $86(6.3)$ \\
\hline $1-5$ years & $189(27.4)$ & $452(66.6)$ & $641(46.8)$ \\
\hline $6-11$ years & $300(43.4)$ & $122(18.0)$ & $422(30.8)$ \\
\hline$>11$ years & $184(26.6)$ & $37(5.5)$ & $221(16.2)$ \\
\hline \multicolumn{4}{|c|}{ Daily income* $(\mathrm{n}(\%))$} \\
\hline US $\$<1.9 /$ day & $296(42.8)$ & $447(65.8)$ & $743(54.2)$ \\
\hline $\begin{array}{l}\text { US\$1.9-3.09/ } \\
\text { day }\end{array}$ & $140(20.3)$ & $111(16.4)$ & $251(18.3)$ \\
\hline US $\$ \geq 3.1 /$ day & $196(28.4)$ & $101(14.9)$ & 297 (21.7) \\
\hline
\end{tabular}

*Missing respondents: 79 due to refusals.

Exchange rate: US\$1=953.8 Myanmar Kyat as of

5 November 2013.

to the interaction between urban-rural location and sex in assessing the association between urban-rural location and TC, we conducted separate regression analyses for men and women (table 4). p Values $<0.05$ were considered to be statistically significant.

\section{RESULTS}

A total of 1370 participants completed all three STEPS, with the response rates at $86 \%$ and $84 \%$ from urban and rural areas, respectively. Table 1 shows the sociodemographic characteristics of the participants. Urban participants were 2 years older than rural participants (49 years vs 47 years). Urban residents attained a higher education and income compared with rural dwellers, and more than half of the participants (54.2\%) earned less than US\$1.9/ day. Only $15 \%$ of rural people and $28 \%$ of the urban population earned US $\$ 3.1$ /day or more (table 1).

In comparison with rural participants, urban dwellers had a significantly higher age-standardised prevalence of hypercholesterolaemia $(50.7 \%$ vs $41.6 \%)$ and a low HDL 
Table 2 Age-standardised + prevalence of dyslipidaemia among 25-74 year-old citizens of the Yangon Region, Myanmar

\begin{tabular}{|c|c|c|c|c|}
\hline & Hypercholesterolaemia & Hypertriglyceridaemia & High LDL & Low HDL \\
\hline & $\%(95 \% \mathrm{Cl})$ & $\%(95 \% \mathrm{Cl})$ & $\%(95 \% \mathrm{Cl})$ & $\%(95 \% \mathrm{Cl})$ \\
\hline \multicolumn{5}{|l|}{ Sex } \\
\hline Male & 48.8 (43.1 to 54.6 ) & 25.1 (20.7 to 30.1$)$ & 11.3 (8.4 to 15.0$)$ & $35.3(29.1$ to 42.1$)$ \\
\hline Female & $44.3(38.0$ to 50.8$)$ & 14.8 (11.0 to 19.7$)$ & 16.3 (12.4 to 21.2$)$ & 70.1 (64.2 to 75.3$)$ \\
\hline p Value $e^{\star \star}$ & 0.243 & $<0.001^{\star}$ & $0.018^{*}$ & $<0.001^{*}$ \\
\hline \multicolumn{5}{|l|}{ Location } \\
\hline Urban & 50.7 (45.1 to 56.4 ) & 20.2 (16.7 to 24.1$)$ & $13.5(9.3$ to 19.1$)$ & 60.6 (55.8 to 65.1$)$ \\
\hline Rural & 41.6 (35.0 to 48.4 ) & 18.0 (11.4 to 27.2$)$ & 15.3 (11.2 to 20.6$)$ & 44.4 (38.0 to 51.0$)$ \\
\hline p Value $e^{\star *}$ & $0.042^{*}$ & 0.583 & 0.564 & $0.001^{*}$ \\
\hline \multicolumn{5}{|l|}{ Education } \\
\hline No formal & 55.3 (50.5 to 60.0$)$ & 23.5 (19.9 to 27.4 ) & $12.0(8.9$ to 15.8$)$ & $47.4(41.8$ to 53.1$)$ \\
\hline $1-5$ years & 42.3 (36.6 to 48.3$)$ & 18.9 (13.2 to 26.4$)$ & $14.6(12.0$ to 17.6$)$ & 52.8 (46.9 to 58.7$)$ \\
\hline $6-11$ years & 55.5 (46.9 to 63.8$)$ & 22.5 (18.5 to 27.1$)$ & 14.8 (9.2 to 22.9$)$ & 46.8 (40.2 to 53.6$)$ \\
\hline$>11$ years & 44.1 (37.7 to 50.6$)$ & 15.5 (11.3 to 20.8$)$ & 14.7 (10.6 to 20.0$)$ & 62.6 (55.4 to 69.2$)$ \\
\hline $\mathrm{p}$ Value ${ }^{\star \star}$ & $0.011^{*}$ & $0.032^{*}$ & 0.692 & $0.031^{*}$ \\
\hline \multicolumn{5}{|l|}{ Income } \\
\hline US\$<1.9/day & 43.3 (36.8 to 50.1$)$ & 19.9 (14.7 to 26.5$)$ & 12.8 (10.1 to 14.9$)$ & 54.2 (48.1 to 60.2$)$ \\
\hline US\$1.9-3.09/day & 51.1 (42.9 to 59.2 ) & 18.9 (15.3 to 23.2) & 15.1 (10.0 to 22.1) & $50.8(44.2$ to 57.4$)$ \\
\hline US $\$ \geq 3.1 /$ day & 50.0 (44.9 to 55.1$)$ & 18.1 (13.1 to 24.4$)$ & 17.4 (12.9 to 23.1$)$ & 53.6 (47.6 to 59.6$)$ \\
\hline p Value & $0.001^{\star}$ & 0.588 & $0.032^{*}$ & 0.407 \\
\hline Total & 46.8 (42.2 to 51.5$)$ & 19.3 (15.4 to 23.9 ) & 14.2 (11.0 to 18.1$)$ & 53.4 (49.7 to 57.1$)$ \\
\hline
\end{tabular}

${ }^{*} p<0.05 ;{ }^{* *} p$ value from Wald test.

†Direct standardisation, based on the 2014 Yangon Region Census population.

HDL, high-density lipoprotein; LDL, low-density lipoprotein.

level $(60.6 \%$ vs $44.4 \%$ ) (table 2$)$. No urban-rural differences were found in the prevalence of hypertriglyceridaemia or high LDL. Men had a similar prevalence of hypercholesterolaemia as women, but a significantly higher age-standardised prevalence of hypertriglyceridaemia (25.1\% vs $14.8 \%$ ), and a lower prevalence of high LDL level (11.3\% vs $16.3 \%)$ and low HDL level $(35.3 \%$ vs $70.1 \%)$. Moreover, we identified no clear pattern in the prevalence of dyslipidaemia by education and income (table 2).

The age-standardised prevalence of severe hypercholesterolaemia was similar in subgroup analysis by gender (2.9\% (95\% CI 2.0 to 4.3 ) in men vs $4.0 \%$ (95\% CI 2.6 to $6.1)$ in women, $\mathrm{p}=0.297)$ and by location $(2.9 \%$ (95\% CI 2.0 to 4.0 ) in urban area vs $4.2 \%$ (95\% CI 3.1 to 5.8 ) in rural area, $\mathrm{p}=0.097$ ) (data not shown in tables).

Age-standardised mean values of TC, TG, LDL and HDL by sex, urban-rural location, education and income levels are presented in table 3. Urban participants had significantly higher mean values of TC, TG and LDL than rural participants, as well as lower HDL levels.

We found no clear pattern in the lipid profiles by income or education (table 3 ).

In multivariate linear regression analyses (table 4, model 1, a), TC was significantly associated with urban location after adjustment for age, sex, education and income, thereby indicating a $0.28 \mathrm{mmol} / \mathrm{L}$ lower mean level of TC in rural than in urban areas (ie, the total effect of urban-rural location). After an additional adjustment for behavioural and metabolic mediators (table 4, model 2 , a), the association between urban-rural location and TC remained significant (ie, the direct effect of urban-rural location). However, the estimate changed only slightly to $0.23 \mathrm{mmol} / \mathrm{L}$, thus indicating that the effect of location was not mediated through the potential mediators of smoking, low fruit and vegetable intake, low physical activity, overweight and obesity, hypertension and diabetes. Due to the presence of a significant interaction between sex and location, we ran separate analyses by sex (table $4, \mathrm{~b}$ and c). The total effect of urban-rural location on TC among men exhibited a $0.39 \mathrm{mmol} / \mathrm{L}$ lower level among rural participants than urban counterparts (table 4, model 1, b). After adjustment for potential behavioural and metabolic mediators (the direct effect), the estimate did not change, indicating that no effect of urban-rural location on TC was mediated through smoking, low fruit and vegetable intake, low physical activity, overweight and obesity, hypertension and diabetes. For women, there was no association between urban-rural location and TC (table 4, b). 
Table 3 Age-standardised $\dagger$ mean values of total cholesterol, triglyceride, low-density lipoprotein and high-density lipoprotein among 25-74 year-old citizens of the Yangon Region, Myanmar

\begin{tabular}{|c|c|c|c|c|}
\hline & $\begin{array}{l}\text { Total cholesterol } \\
\text { (mmol/L) }\end{array}$ & $\begin{array}{l}\text { Triglyceride } \\
\text { (mmol/L) }\end{array}$ & $\begin{array}{l}\text { LDL } \\
\text { (mmol/L) }\end{array}$ & $\begin{array}{l}\text { HDL } \\
\text { (mmol/L) }\end{array}$ \\
\hline & Mean (SE) & Mean (SE) & Mean (SE) & Mean (SE) \\
\hline \multicolumn{5}{|l|}{ Sex } \\
\hline Male & $5.21(0.045)$ & $1.67(0.057)$ & $3.24(0.045)$ & $1.19(0.013)$ \\
\hline Female & $5.19(0.044)$ & $1.41(0.037)$ & $3.39(0.035)$ & $1.14(0.018)$ \\
\hline Urban & $5.31(0.044)$ & $1.65(0.049)$ & $3.44(0.019)$ & $1.11(0.010)$ \\
\hline Rural & $5.05(0.068)$ & $1.38(0.078)$ & $3.16(0.058)$ & $1.25(0.012)$ \\
\hline$p$ Value ${ }^{\star *}$ & $0.009^{*}$ & $0.017^{\star}$ & $0.001^{*}$ & $<0.001^{*}$ \\
\hline \multicolumn{5}{|l|}{ Education } \\
\hline$>11$ years & $5.13(0.051)$ & $1.57(0.063)$ & $3.33(0.032)$ & $1.11(0.020)$ \\
\hline p Value ${ }^{* *}$ & $0.009^{\star}$ & 0.466 & $0.014^{*}$ & 0.121 \\
\hline \multicolumn{5}{|l|}{ Income } \\
\hline US $\$<1.9 /$ day & $5.14(0.047)$ & $1.50(0.050)$ & $3.28(0.046)$ & $1.16(0.018)$ \\
\hline US\$1.9-3.09/day & $5.28(0.053)$ & $1.59(0.053)$ & $3.37(0.047)$ & $1.18(0.011)$ \\
\hline US $\$ \geq 3.1 /$ day & $5.25(0.063)$ & $1.52(0.058)$ & $3.37(0.053)$ & $1.16(0.019)$ \\
\hline$p$ Value ${ }^{* *}$ & 0.120 & 0.154 & 0.058 & 0.538 \\
\hline Total & $5.21(0.041)$ & $1.54(0.044)$ & $3.32(0.037)$ & $1.17(0.011)$ \\
\hline
\end{tabular}

${ }^{*} \mathrm{p}<0.05 ;{ }^{* *} \mathrm{p}$ value from Wald test.

†Direct standardisation, based on the 2014 Yangon Region Census population.

HDL, high-density lipoprotein; LDL, low-density lipoprotein.

Table 4 Effect† of urban-rural location on total cholesterol among 25-74 year-old citizens of the Yangon Region, Myanmar

\begin{tabular}{|c|c|c|c|c|c|c|}
\hline & \multicolumn{2}{|l|}{ Crude } & \multicolumn{2}{|l|}{$\begin{array}{l}\text { Model } 1 \\
\text { Total effect } \neq\end{array}$} & \multicolumn{2}{|l|}{$\begin{array}{l}\text { Model } 2 \\
\text { Direct effect§ }\end{array}$} \\
\hline & $\begin{array}{l}\text { Coefficient } \\
(95 \% \mathrm{Cl})\end{array}$ & p Value & $\begin{array}{l}\text { Coefficient } \\
(95 \% \mathrm{Cl})\end{array}$ & p Value & $\begin{array}{l}\text { Coefficient } \\
(95 \% \mathrm{Cl})\end{array}$ & p Value \\
\hline a. Urban location & (Ref) & & (Ref) & & (Ref) & \\
\hline Rural location & $\begin{array}{l}-0.28 \\
(-0.50 \text { to }-0.05)\end{array}$ & $0.020^{\star}$ & $\begin{array}{l}-0.28 \\
(-0.44 \text { to }-0.01)\end{array}$ & $0.042^{*}$ & $\begin{array}{l}-0.23 \\
(-0.42 \text { to }-0.04)\end{array}$ & $0.026^{\star}$ \\
\hline Rural man & $\begin{array}{l}-0.49 \\
(-0.79 \text { to }-0.19)\end{array}$ & $0.005^{\star}$ & $\begin{array}{l}-0.39 \\
(-0.74 \text { to }-0.29)\end{array}$ & $0.037^{*}$ & $\begin{array}{l}-0.39 \\
(-0.75 \text { to }-0.01)\end{array}$ & $0.041^{*}$ \\
\hline c. Urban woman & (Ref) & & (Ref) & & (Ref) & \\
\hline Rural woman & $\begin{array}{l}-0.07 \\
(-0.33 \text { to } 0.20)\end{array}$ & 0.586 & $\begin{array}{l}-0.03 \\
(-0.27 \text { to } 0.20)\end{array}$ & 0.762 & $\begin{array}{l}-0.02 \\
(-0.23 \text { to } 0.18)\end{array}$ & 0.797 \\
\hline
\end{tabular}

${ }^{*} \mathrm{p}<0.05$.

†Linear regression.

$\ddagger$ Model 1: adjusted for age, sex, income and education.

§Model 2: adjusted for age, sex, income, education, smoking, low fruit and vegetable intake, low physical activity, overweight and obesity,

hypertension and diabetes. 


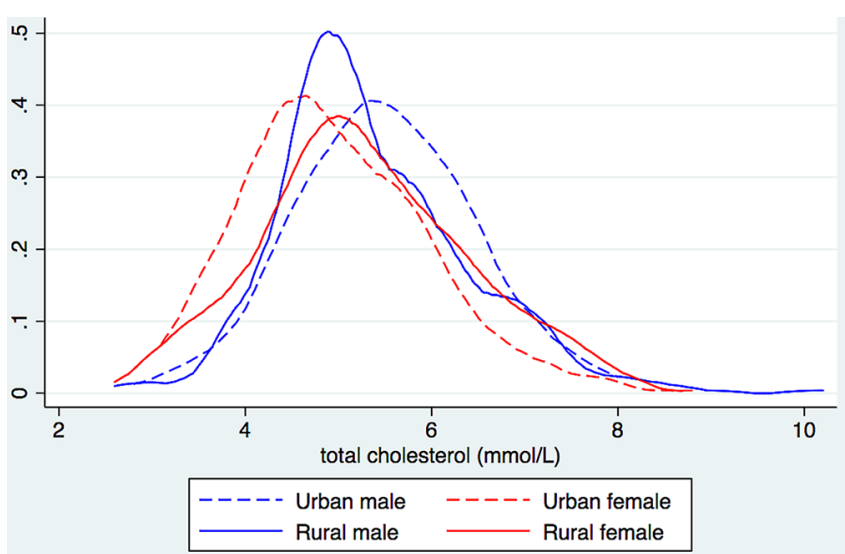

Figure 1 Distribution of total cholesterol level by urban-rural location and gender among 25-74 year-old citizens of the Yangon Region, Myanmar.

The distribution of TC also revealed a significant difference between urban and rural men, which is illustrated in figure 1.

\section{DISCUSSION}

The prevalence of hypercholesterolaemia was alarmingly high in the Yangon Region, Myanmar, and higher in urban than rural areas. The higher levels of TC concentration, TGs and LDL, and the lower level of HDL among urban than rural participants, indicate an unhealthier lipid profile in urban than rural citizens. Among men, TC was significantly associated with urban location.

The strengths of the present study were the use of a similar methodology in the urban and rural studies, in addition to the high response rates in both studies, therefore minimising potential information and selection bias, respectively. We excluded from the sampling frame soldiers, institutionalised people, monks and nuns, who might have differed from the participants in terms of physical activity and dietary habits, which may have led to an overestimation or underestimation of the prevalence and mean blood lipid values. The lipid status of these groups of the population is not known in Myanmar. Thus, the direction of the potential bias is unknown. A limitation from the present cross-sectional study is the lack of information about awareness, treatment with cholesterol-lowering medicine and control of hypercholesterolaemia. Consequently, it may have led to an underestimation of the prevalence, and led to associations towards the null value. It is a limitation that we did not assess the fat composition of the diet of participants so that we could have included the variable as a mediator in analyses of the direct effect of urban-rural location on TC. Information bias may have been introduced from the questions on self-reported behavioural risk factor such as smoking. Nonetheless, it is likely that under-reporting will be similar in different subgroups of the population. ${ }^{23}{ }^{24}$

Despite a reduction in cholesterol levels in some regions, South-East Asian countries have faced a rise in the TC level in both men and women. ${ }^{5}$ Our findings support this increasing trend when comparing results with a study conducted in the same region of Myanmar 10 years earlier ${ }^{7}$; the mean TC level increased from 4.47 to $5.23 \mathrm{mmol} / \mathrm{L}$ in men, and from 4.83 to $5.33 \mathrm{mmol} / \mathrm{L}$ in women. Additionally, we reported a higher concentration of TC than the global estimates of $4.64 \mathrm{mmol} / \mathrm{L}$ in men and $4.76 \mathrm{mmol} / \mathrm{L}$ in women. ${ }^{5}$ Regarding hypercholesterolaemia, when comparing the previous study from the Yangon Region conducted 10years ago, we detected an increasing trend from $21.6 \%$ to $48.8 \%$ in men and from $35.1 \%$ to $44.3 \%$ in women, ${ }^{7}$ a trend that is in line with the findings from the South-East Asian countries. ${ }^{5}$

We speculate that the increasing trend in $\mathrm{TC}$ and hypercholesterolaemia, and the current high values in the Yangon Region, are due to the use of unhealthy oils for food preparation and/or a generally high intake of oil-rich food, the practice of a more sedentary lifestyle, especially in urban areas, and a low fruit/vegetable intake.

Recent societal changes and rapid urbanisation in Myanmar have sped up this change in lifestyle, particularly in urban areas. Consequently, in comparison with rural people, urban people can more easily access junk food, oily-preserved foods and already-cooked meals in the street of the cities. In Myanmar, men are most commonly the breadwinners, thus working outside the house to earn money for the family, which exposes them more than women to such oily foods on a daily basis. Additionally, hard manual employment in the rural areas may keep rural men at a lower risk for hypercholesterolaemia than their urban counterparts.

There is a Myanmar proverb that reads, 'Se Ko Yay Choe; Say-Yoe Mee Hlone,' meaning 'Bathing in oil and making a bonfire with tobacco.' It is a sign of being affluent if you use plenty of oil and tobacco. A traditional Myanmar custom is the repeated reuse of oil for frying food, and hence the ingestion of saturated fats, thereby leading to abnormal lipid profiles of the population.

The poor economic situation in Myanmar causes people in both urban and rural areas to reuse cooking oils and keep prepared foods in oil to keep them edible for a longer period without needing to be refrigerated. Another contributor to the high cholesterol level could be the low consumption of fruits and vegetables in the Yangon Region. ${ }^{16}$ The majority of the population, $97 \%$ in rural areas and $85 \%$ in the urban areas of the Yangon Region, consumed less fruits and vegetables than recommended by the WHO. ${ }^{16}$ A higher consumption of these foods would help in reducing unhealthy cholesterol levels (TC and LDL). ${ }^{25}$

The present finding of no clear pattern between income levels and dyslipidaemia is in contrast with findings from both Malaysia ${ }^{26}$ and Nigeria. ${ }^{27}$ Although there was a low prevalence of severe hypercholesterolaemia, care should be taken.

Our findings of no association between TC and urban location among women are in contrast to a study from India, which demonstrated a higher prevalence among urban than rural women. ${ }^{28}$ 
This study has been conducted in the most developed and the most populated area of Myanmar, thereby making it difficult to generalise findings to the whole of Myanmar. However, there is a lot of similarity in lifestyles and dietary habits across the country, so to a certain degree the findings may actually be representative for other rural areas and the large cities of Myanmar.

Since the occurrence of hypercholesterolaemia is high, further analyses should be performed for the purpose of preventive strategies. Preventive measures aimed at lowering abnormal lipid profiles among the people of Myanmar should be implemented, and tailored to the Myanmar context. Changes in the prevalence of hypercholesterolaemia among men and women in urban and rural areas should be further studied, as well as the identification of the determinants of unfavourable lipid values.

\section{CONCLUSION}

The mean level of TC and the prevalence of hypercholesterolaemia were alarmingly high in men and women in both the urban and rural areas of the Yangon Region, Myanmar. TC and hypercholesterolaemia are proven risk factors for coronary heart diseases; for this reason, preventive measures to reduce cholesterol levels in the population are urgently needed.

\section{Author affiliations}

${ }^{1}$ Institute of Health and Society, Faculty of Medicine, University of Oslo, 0slo, Norway

${ }^{2}$ International Relations Division, Ministry of Health and Sports, Nay Pyi Taw, Myanmar

${ }^{3}$ Epidemiology Unit, Prince of Songkla University, Songkla, Thailand

${ }^{4}$ University of Pharmacy, Yangon, Yangon, Myanmar

${ }^{5}$ University of Medicine 1, Yangon, Yangon, Myanmar

${ }^{6}$ University of Nursing, Yangon, Yangon, Myanmar

${ }^{7}$ University of Dental Medicine, Mandalay, Mandalay, Myanmar

${ }^{8}$ Military Institute of Nursing and Paramedical Sciences, Yangon, Myanmar

${ }^{9}$ University of Pharmacy, Mandalay, Mandalay, Myanmar

${ }^{10} \mathrm{Health}$ and Disease Control Unit, Directorate of Medical Services, Nay Pyi Taw,

Myanmar

${ }^{11}$ University of Dental Medicine, Yangon, Yangon, Myanmar

${ }^{12}$ University of Nursing, Mandalay, Mandalay, Myanmar

${ }^{13}$ Department of Public Health, Nay Pyi Taw, Myanmar

${ }^{14}$ Defence Services Medical Academy, Yangon, Myanmar

${ }^{15}$ University of Public Health, Yangon, Myanmar

${ }^{16}$ University of Traditional Medicine, Mandalay, Myanmar

${ }^{17}$ University of Medicine, Mandalay, Mandalay, Myanmar

${ }^{18}$ Faculty of Medicine, SEGi University, Petaling Jaya, Malaysia

Contributors ASH and EB contributed to the study design and the statistical analyses. ASH drafted the manuscript, while coauthors gave input to the drafts. MKRK, WPA, ANMM, WTA, MMW, TTN, EMH, PPS, NWYT, NA, MMK, AKH, ST, PT, TL, SSW, TTA, KAT, WWAP, GST, TTN, TMT, KSM, KKO, NKMM, SMN, KKZ, MBB, LYS and WMO contributed to the conception and study design, identification of the objectives, and also carried out the statistical analyses and interpretation of the data. HS contributed to the statistical analyses and interpretation of the data. All the authors read and approved the final manuscript.

Funding The study was funded by the Norad/NORHED Project: MMY-13/0049 'Health and Sustainable Development in Myanmar-Competence Building in Public Health and Medical Research and Education (MY-NORTH)'.

Competing interests None declared.
Ethics approval Ethical approval was obtained from the Department of Health, Ministry of Health, Myanmar, and from the Norwegian Regional Committees for Medical and Health Research Ethics (REK).

Provenance and peer review Not commissioned; externally peer reviewed.

Data sharing statement The data set supporting the conclusion of this article is available upon request to ASH (aungsh@gmail.com).

Open Access This is an Open Access article distributed in accordance with the Creative Commons Attribution Non Commercial (CC BY-NC 4.0) license, which permits others to distribute, remix, adapt, build upon this work non-commercially, and license their derivative works on different terms, provided the original work is properly cited and the use is non-commercial. See: http://creativecommons.org/ licenses/by-nc/4.0/

(C) Article author(s) (or their employer(s) unless otherwise stated in the text of the article) 2017. All rights reserved. No commercial use is permitted unless otherwise expressly granted.

\section{REFERENCES}

1. Lewington S, Whitlock G, Clarke R, et al. Blood cholesterol and vascular mortality by age, sex, and blood pressure: a meta-analysis of individual data from 61 prospective studies with 55,000 vascular deaths. Lancet 2007;370:1829-39.

2. Erqou S, Kaptoge S, Perry PL, et al. Lipoprotein(a) concentration and the risk of coronary heart disease, stroke, and nonvascular mortality. JAMA 2009;302:412-23.

3. GBD 2015 Mortality and Causes of Death Collaborators. Global, regional, and national life expectancy, all-cause mortality, and causespecific mortality for 249 causes of death, 1980-2015: a systematic analysis for the Global Burden of Disease Study 2015. Lancet 2016;388:1459-544.

4. Institute for Health Metrics And Evaluation. GBD Compare Data Visualization. Seattle, WA: IHME, University of Washington, 2017. http://vizhub.healthdata.org/gbd-compare. (accessed 23 Mar 2017).

5. Farzadfar F, Finucane MM, Danaei G, et al. National, regional, and global trends in serum total cholesterol since 1980: systematic analysis of health examination surveys and epidemiological studies with 321 country-years and 3.0 million participants. Lancet 2011;377:578-86.

6. Ala Alwan TA, Bettcher D, Branca F, et al. Global status report on noncommunicable diseases 2010.World Health Organization. 2011 (accessed 19 Mar 2017)

7. Latt TS, Aung PP, Min T, et al. WHO STEP wise approach to NCD surveillance, Yangon division.Myanmar (2003-2004) Standard Report, 2004.

8. Sanders K, Johnson L, O'Dea K, et al. The effect of dietary fat level and quality on plasma lipoprotein lipids and plasma fatty acids in normocholesterolemic subjects. Lipids 1994;29:129-38.

9. Pados G. [Modern diet for patients with hyperlipoproteinemia]. Orv Hetil 1993;134:787-96.

10. Durstine JL, Grandjean PW, Cox CA, et al. Lipids, lipoproteins, and exercise. J Cardiopulm Rehabil 2002;22:385-98.

11. Mannu GS, Zaman MJ, Gupta A, et al. Evidence of lifestyle modification in the management of hypercholesterolemia. Curr Cardiol Rev 2013;9:2-14.

12. Law MR, Wald NJ, Thompson SG. By how much and how quickly does reduction in serum cholesterol concentration lower risk of ischaemic heart disease? BMJ 1994;308:367-72.

13. Ministry of Immigration and Population, Department of Population. The 2014 Myanmar population and housing census; Yangon region, census report volume 3 - L. 2015 http://countryoffice.unfpa.org/ myanmar/2014/01/21/8918/census_printed_materials/, http://www. dop.gov.mm/ (accessed 19 Mar 2017).

14. World Health Organization. WHO STEPS surveillance manual the WHO STEPwise approach to chronic disease risk factor surveillance. 2005 http://www.who.int/chp/steps/STEPS_Manual.pdf?ua=1 (accessed 15 Mar 2017).

15. World Health Organization. STEPS Sample Size Calculator. 2008 http://www.who.int/chp/steps/resources/sampling/en/ (accessed 19 Mar 2017).

16. Htet AS, Bjertness MB, Sherpa LY, et al. Urban-rural differences in the prevalence of non-communicable diseases risk factors among 25-74 years old citizens in Yangon Region, Myanmar: a cross sectional study. BMC Public Health 2016;16:1225 http://www.ncbi. nlm.nih.gov/pubmed/27919240.

17. Kjøllesdal M, Htet AS, Stigum $\mathrm{H}$, et al. Consumption of fruits and vegetables and associations with risk factors for non-communicable 
diseases in the Yangon region of Myanmar: a cross-sectional study. BMJ Open 2016;6:e011649.

18. National Cholesterol Education Program (NCEP) Expert Panel on Detection, Evaluation, and Treatment of High Blood Cholestero in Adults (Adult Treatment Panel III). Third report of the National Cholesterol Education Program (NCEP) Expert Panel on Detection, Evaluation, and Treatment of High Blood Cholesterol in Adults (Adult Treatment Panel III) final report. Circulation 2002;106:3143-421.

19. Santos RD, Gidding SS, Hegele RA, et al. Defining severe familial hypercholesterolaemia and the implications for clinical management: a consensus statement from the International Atherosclerosis Society Severe Familial Hypercholesterolemia Panel. Lancet Diabetes Endocrinol 2016;4:850-61.

20. Sniderman AD, Tsimikas S, Fazio S. The severe hypercholesterolemia phenotype: clinical diagnosis, management, and emerging therapies. J Am Coll Cardiol 2014;63:1935-47.

21. The World Bank. An online analysis tool for global poverty monitoring The World Bank. PovcalNet, 2016 (6 Oct 2015. http://iresearch. worldbank.org/PovcalNet/index.htm. (accessed 19 Mar 2017).

22. World Health Organization. Definition and diagnosis of diabetes mellitus and intermediate hyperglycemia report of a WHO/IDF consultation, 2006. http://www.who.int/diabetes/publications/ Definition and diagnosis of diabetes_new.pdf. (accessed 19 May 2016).
23. Yeager DS, Krosnick JA. The validity of self-reported nicotine product use in the 2001-2008 National Health and Nutrition Examination Survey. Med Care 2010;48:1128-32.

24. Park SW, Kim JY. Validity of self-reported smoking using urinary cotinine among vocational high school students. J Prev Med Public Health 2009;42:223-30.

25. Vartiainen $\mathrm{E}$, Laatikainen $\mathrm{T}$, Tapanainen $\mathrm{H}$, et al. Changes in serum cholesterol and diet in North Karelia and all Finland. Glob Heart 2016;11:179-84.

26. Amiri M, Majid HA, Hairi F, et al. Prevalence and determinants of cardiovascular disease risk factors among the residents of urban community housing projects in Malaysia. BMC Public Health 2014;14:S3.

27. Oguoma VM, Nwose EU, Skinner TC, et al. Prevalence of cardiovascular disease risk factors among a Nigerian adult population: relationship with income level and accessibility to CVD risks screening. BMC Public Health 2015;15:397.

28. Pandey RM, Gupta R, Misra A, et al. Determinants of urban-rural differences in cardiovascular risk factors in middle-aged women in India: a cross-sectional study. Int J Cardiol 2013;163:157-62.

29. Friedewald WT, Levy RI, Fredrickson DS. Estimation of the concentration of low-density lipoprotein cholesterol in plasma, without use of the preparative ultracentrifuge. Clin Chem 1972;18:499-502. 